\title{
Design e Esporte: análise emocional da Camisa Chapecoense II 2018 s/no La Pasion
}

\section{Design and Sport: emotional analysis of Chapecoense II 2018 s/no La Pasion Shirt}

\author{
Letícia Casagrande Dal Bello \\ Mestranda em Design de Moda e Vestuário pela Universidade do Estado de Santa Catarina (Udesc) - \\ contato@gingerconsultoria.com - orcid.org/0000-0003-4046-5497 \\ Luana Ferreira Graziano \\ Mestranda em Moda pela Universidade do Estado de Santa Catarina (Udesc) - luana.ferreira.graziano@gmail.com - \\ orcid.org/0000-0002-7784-3378 \\ Célio Teodorico dos Santos \\ Doutor em Curso Engenharia Mecânica pela Universidade Federal de Santa Catarina (UFSC). Professor na Universidade \\ do Estado de Santa Catarina (Udesc) - celio.teodorico@gmail.com - orcid.org/0000-0001-9809-5658 \\ Fabiana Rodrigues da Silva \\ Mestranda em Design de Moda e Vestuário pela Universidade do Estado de Santa Catarina (Udesc) - \\ bia.rodriguesrj@yahoo.com - orcid.org/0000-0002-6015-3370 \\ Ricardo de Moura Mendonça \\ Bacharel em Arquitetura pela Faculdade Barddal de Artes Aplicadas. Professor na Faculdade Cesusc - \\ ricomendonca@gmail.com - orcid.org/0000-0002-5764-6852 \\ Fabíola Barbosa Beltrão \\ Mestre em Design de Vestuário e Moda pela Universidade do Estado de Santa Catarina (Udesc) - \\ phabbyolla@gmail.com - orcid.org/0000-0002-6705-0112
}

\section{Resumo}

Objetiva a análise emocional da camisa do time de futebol Chapecoense, denominada Camisa Chapecoense II 2018 s/n La Pasion, que utiliza das cores da bandeira da Colômbia com o escudo da Chapecoense, em forma de homenagem remetendo ao apoio dado no acidente aéreo ocorrido no país no ano de 2016. Conduziu-se um questionário com 14 emoções relacionadas ao design emocional a fim de obter dados para a compreensão sobre o assunto. Evidenciou que $82 \%$ dos participantes da pesquisa eram torcedores do time e a maioria respondeu positivamente ao objeto apresentado. Entre os respondentes não torcedores, também foi observado que uma porção significativa sentiu algum tipo de emoção em relação a camisa. Realizou-se a análise do artefato por meio de pesquisa com dados do questionário aplicado e documentaram-se os resultados, com embasamento em autores como Desmet (2002) e Norman (2008) e conceitos da psiquiatria.

Palavras-chave: Design. Análise emocional. Chapecoense. Vestuário.

\begin{abstract}
Was aimed at the emotional analysis of Chapecoense' soccer team shirt named Chapecoense II 2018 s/no La Pasion, which uses the colors of the Colombian flag with the shield of Chapecoense, as a tribute referring to the support given in the plane crash with the football team in the country in 2016. Thus a questionnaire with 14 emotions related to emotional design was conducted in order to obtain data for a better understanding of the subject. Showed that $82 \%$ of respondents were fans of the team and the vast majority responded positively to the subject presented. Among non-fan respondents, it was also observed that a significant portion experienced some kind of emotion regarding the shirt. The analysis was performed through research with in the questionnaire data applied and documented the results, based on authors such as Desmet (2002) and Norman (2008) and concepts of psychiatry.
\end{abstract}

Keywords: Design. Emotional analysis. Chapecoense. Clothing. 


\section{INTRODUÇÃO}

O que torna as coisas boas ou ruins? Por que se ama ou se detesta algo ou alguma coisa? A emoção tem um papel basilar na capacidade humana de compreender o mundo e a forma como se lida com as coisas. Por ser resposta do organismo a um estímulo, tais impactos causam emoções, as quais muitas vezes são refletidas em ações.

Damásio $(2004$; 2012) explana que a emoção pode ser considerada um reflexo do comportamento do corpo, capaz de expressar sentimentos transmitidos de forma consciente pela mente, tornado possível através do contato físico ou visual que o indivíduo pode exercer com os produtos, reafirmando que essa relação dos indivíduos com os objetos do dia-a-dia é um fator essencial na geração das emoções - podendo ser tanto positivas quanto negativas, automáticas ou inconscientes, dependendo do meio no qual o indivíduo está inserido.

Tendo em vista o volume crescente de ofertas de produtos, o designer considera novos meios e estratégias, buscando uma melhor compreensão a respeito dos hábitos e ações de seu público alvo, de forma que essa abordagem possa auxiliar, ou contribuir na decisão de escolha, e aquisição de produtos por parte dos indivíduos. Para tal êxito, o Design Emocional atua como uma perspectiva de estimular as emoções dos indivíduos criando uma experiência capaz de levar a uma ação - concebendo para isto a humanização do objeto, trabalhando com os aspectos subjetivos, das funcionalidades e emocionais, transformados em atributos do produto. De acordo com Norman (2008), esses estímulos podem estar presentes nos níveis visceral, comportamental e reflexivo esses níveis são estruturas do cérebro que explicam as diferentes reações emocionais originadas das interações e experiência com produtos. O nível visceral é relativo à aparência e nosso primeiro contato visual com as coisas; o nível comportamental conecta-se com as funções do produto, evidenciado no desempenho e usabilidade, tem uma ligação natural com as relações fisiológicas provocadas pelas interações com produtos, e por último o nível reflexivo, afetado pela cultura, experiência, lembranças, sentimentos e satisfação pessoal, essas características assumem uma dimensão simbólica oriunda do repertório de cada indivíduo.

O propósito deste artigo consiste em explanar, por meio de um estudo de caso, a análise das emoções da edição especial da camisa da Chapecoense em homenagem à Colômbia, país no qual o time de futebol e seus representantes (bem como jornalistas e convidados) estiveram envolvidos em um acidente aéreo rumo à cidade de Medellín, em novembro de 2016. 
Partindo do conceito de que método é um procedimento para alcançar determinado fim e que a finalidade da ciência é a busca do conhecimento, pode-se dizer que o método científico é um conjunto de procedimentos adotados com o propósito de atingir o conhecimento (FONSECA, 2002). Marconi e Lakatos (2017) afirmam que os métodos científicos também podem ser utilizados na resolução de problemas do cotidiano, todavia, não há produção de ciência sem a aplicação de métodos científicos.

Segundo Gil (2008), a pesquisa científica é composta por procedimentos sistemáticos baseados no raciocínio lógico, com o objetivo de encontrar soluções para problemas mediante métodos científicos. Com base nas colocações de autores como Gil (2008) e Marconi e Lakatos (2017), pode-se classificar este artigo como de caráter básico e qualitativo, visto que utiliza de pesquisa bibliográfica para elucidação do estudo de design emocional, e um questionário aplicado como instrumento de coleta de dados para a análise do objeto, cujas informações resultam no contexto do design emocional aplicado na construção da imagem do vestuário e o seu valor para o produto como um todo.

\section{FUNDAMENTAÇÃO TEÓRICA}

\subsection{Design emocional e o vestuário de moda}

As emoções são essenciais para estimular a curiosidade dos indivíduos e sua capacidade de aprendizado, ampliando os repertórios de pensamento-ação, encorajando-os a descobrir novas linhas de raciocínio ou ação. De forma a elucidar este capítulo e os parâmetros para a análise do objeto, optou-se pela utilização de diferentes autores, com destaque para Norman (2008) e Desmet (2002), por serem pioneiros e de grande referência nas áreas do design e emoção aplicados aos artefatos. Norman (2008) conceitua que as respostas dos seres humanos aos artefatos são determinadas por diferentes fatores, os quais podem ser provenientes do designer e fabricante, da propaganda e elementos como imagem de marca ou de experiências pessoais. Piffero e Pizzato (2018) afirmam que são as propriedades intangíveis que tornam os produtos competitivos num contexto nos quais os artefatos se equivalem tecnicamente. Cietta (2017) argumenta que a preferência no momento da escolha de uma roupa é feita muito mais por seus atributos imateriais do que pelos técnicos. Da mesma forma, Garcia e Miranda (2005) argumentam que o objetivo na 
compra de produtos é a pessoa ver seus gostos e valores refletidos neles, uma certa identificação social para o produto representar a personalidade do usuário.

O design emocional, de acordo com Norman (2008), pode ser explicado como sendo composto por três níveis - o visceral, o comportamental e o reflexivo - cada um desempenha seu papel para dar forma à experiência humana e requer em cada nível uma abordagem diferente por parte do designer.

Como parte dos seus estudos, Norman (2008) considera o nível visceral como o que a natureza faz, em razão de os seres humanos perceberem sinais emocionais advindos do ambiente, assim como realizam o julgamento aparente de algum artefato, seu impacto emocional imediato e seus aspectos físicos, interpretados automaticamente neste nível. O autor supracitado argumenta que os princípios ocultos do design visceral são predeterminados, consistentes entre povos e culturas.

O nível comportamental deve centrar-se no ser humano, concentrando-se na usabilidade e em compreender e satisfazer as necessidades de quem o utiliza, embora o indivíduo ainda não as tenha manifestado ou mesmo percebido, não é relevante aqui sua aparência e o raciocínio lógico. Neste nível, interessa o desempenho e os seus quatro componentes principais: funcionalidade, usabilidade, sensação física e compreensibilidade. Por isso, Norman (2008, p. 93) argumenta que "o primeiro passo do bom design comportamental é compreender exatamente como as pessoas vão usar um produto". Desta forma, é no design comportamental que os profissionais de usabilidade enfocam seus estudos.

Por fim, o terceiro nível do Design Emocional é o nível reflexivo. Este diz respeito à mensagem, à cultura, à autoimagem, ao significado de um produto, seu uso ou às lembranças pessoais que algo evoca. Sua essência consiste em que tudo está na mente do observador. Miranda (2008) diz que os produtos têm valores os quais excedem o funcional, devido sua capacidade de transmitir significados, sendo símbolos através dos quais o indivíduo comunica sobre si para si mesmo e para os outros. Para Norman (2008, p. 111), "as operações de nível reflexivo frequentemente determinam a impressão global que uma pessoa tem de um produto. É quando você se recorda do produto, refletindo sobre seu apelo total e a experiência de usá-lo". Proni (2008) explica que o significado vem da interpretação, sendo esta sua verdade única. Para o autor supracitado, o significado depende do receptor e sua bagagem, do que ele pensa, sabe, deseja, de 
suas opiniões, cultura, faixa etária e afins. No produto elencado como objeto de análise, são perceptíveis os elementos capazes de agirem no nível reflexivo, evocando emoções referentes à mensagem implícita e seu significado, especialmente em relação às memórias e empatia evocados.

Os estudos para medir os estímulos emocionais das interações com produtos e serviços é recente e os resultados dessas investigações são trabalhados por diferentes autores, com o intuito de estabelecer diretrizes e estruturas metodológicas a serem utilizadas por desenvolvedores de produtos.

Desmet e Hekkert (2001), apresentam um modelo básico das emoções de produtos e tratam a emoção como uma preocupação do indivíduo; neste modelo, os autores afirmam que os usuários de produtos possuem três tipos de objetivos na relação com produtos: o primeiro é um objetivo utilitário, o qual se assemelha ao nível comportamental apresentado por Norman; o segundo é uma meta social que pode ser visto como dimensão simbólica de ascensão social e status, e o terceiro é hedonista, relacionado ao prazer.

As preocupações emocionais advindas das interações dos indivíduos com produtos e serviços estão carregadas de estímulos positivos ou negativos, ou seja, são provocadas por uma avaliação pessoal de significado no atendimento de suas necessidades. Neste contexto, o artigo se propõe a fazer uma avaliação emocional da camisa do time de futebol Chapecoense denominada Camisa Chapecoense II 2018 s/no La Pasion, que utiliza das cores da bandeira da Colômbia com o escudo da Chapecoense, em forma de homenagem ao apoio dado no acidente aéreo ocorrido no país no ano de 2016. Apesar da complexidade do estudo, dado ao grau de subjetividade, o trabalho é oportuno para o campo, ao considerar que os produtos são adquiridos primeiro pela sua significação, e não por suas funcionalidades. Para Jordan (2000), os resultados dos benefícios emocionais poderiam ser proporcionados aos usuários pelos prazeres físico, social, psíquico e ideológico.

O vestuário de moda é uma forma de comunicação não-verbal de valores sociais e individuais utilizada pelo indivíduo para identificação, expressando a sua personalidade, caráter e sentimentos. Crane (2006, p. 22) explica que "as roupas, como artefatos, 'criam' comportamentos por sua capacidade de impor identidades sociais e permitir que as pessoas afirmem identidades sociais latentes". Miranda (2008) complementa ao afirmar que as roupas possuem um consumo altamente simbólico, em virtude de as pessoas avaliarem as demais pelo que veem, incluindo aqui 
estilos, marcas, uniformes e subculturas; ainda, esclarece que as questões simbólicas são importantes, e fatores como exclusividade e originalidade têm seu valor perante o consumidor, mas questões como qualidade e conforto são básicas para que os aspectos simbólicos sejam estabelecidos e considerados, reforçando a importância dos três níveis de design emocional acima citados, de modo a complementarem-se.

Com foco no aspecto emocional, ou nível reflexivo, por meio de diversos estudos e testes na área de design e emoção, Desmet (2002) conseguiu resumir a 14 as emoções mensuráveis relativas a aparência dos produtos, sendo sete positivas e sete negativas. As emoções consideradas positivas são: fascinação, surpresa agradável, admiração, inspiração, desejo, diversão e satisfação. As emoções consideradas negativas são: nojo, surpresa desagradável, desprezo, indignação, insatisfação, desapontamento e tédio. Estas "[...] representam uma seção transversal gerenciável de todas as emoções que podem ser provocadas pela aparência do produto" (DESMET, 2002, p. 65, tradução nossa).

Optou-se por utilizar este autor, pois se considera que seus estudos dos atributos se encaixam na perspectiva do objeto. Para este estudo, também foram aplicadas 14 emoções, porém estas foram divididas em formato adaptado ao de Desmet (2002). Foram selecionadas as seguintes oito emoções consideradas positivas: orgulho, desejo, esperança, alegria, interesse, encantamento, diversão e satisfação. As seis emoções consideradas negativas foram: tédio, medo, indiferença, aversão, desprezo e tristeza. As emoções selecionadas são de rápida e intuitiva compreensão, facilitando o processo de resposta dos respondentes ao questionário, no intuito de se obter resultados mais assertivos. Ainda, para o questionário foram utilizadas palavras em vez de animações - originalmente utilizadas pelo autor em seus estudos - para evitar interpretação errônea das emoções por parte dos respondentes do questionário.

Após estudo prévio e seleção das emoções para esta pesquisa, sentiu-se a necessidade de uma breve análise pelo viés da Psiquiatria a respeito de possíveis causas para que uma emoção seja sentida ou não pelo indivíduo na iminência de uma relação mais profunda com um determinado objeto. Para tal, buscou-se na literatura existente a expectativa de obter respostas por meio de um estudo a respeito de transtornos emocionais causados por um evento traumático, cujas consequências poderiam afetar o comportamento, e neste caso, o consumo ou não de um objeto em específico, o qual pudesse despertar a lembrança do fato ocorrido. 


\title{
2.2 Transtorno de Estresse Pós-Traumático (TEPT)
}

O termo TEPT - Transtorno de Estresse Pós-Traumático - começou a ser usado na década de 1970 para descrever o diagnóstico de veteranos norte-americanos da Guerra do Vietnã. A Associação Americana de Psiquiatria reconheceu o termo em 1980, durante a publicação da terceira versão do Manual Diagnóstico e Estatística de Transtornos Mentais (APA, 2014).

Dentro da Psiquiatria, existem vários estudos de TEPT, uma perturbação mental que pode se desenvolver em resposta à exposição a um evento traumático, como agressão sexual, guerra, acidente de viação ou outro tipo de ameaça à vida da pessoa. O diagnóstico baseia-se na presença de sintomas específicos na sequência de um evento traumático (BISSON, 2013, tradução nossa), cujos sintomas mais comuns são: pensamentos, sentimentos ou sonhos perturbadores relacionados com o evento traumático; estresse físico ou psicológico perante a exposição a indícios ou recordações do trauma; esforço para evitar situações que recordem ao trauma; alterações na forma de pensar e sentir; aumento da reação de lutar ou fugir - sintomas estes que estarão presentes durante mais de um mês após o evento (APA, 2014). Como elucida Freitas (2013, online):

\begin{abstract}
Duas áreas do cérebro primordialmente afetadas no TEPT são a amígdala cerebral e o hipocampo. A amígdala parece ter papel importante na percepção, no reconhecimento e na formação da memória, especialmente naquela relacionada a estímulos de caráter emocional, gerando associações através das conexões cerebrais. O hipocampo tem como função principal a memória declarativa (ou explícita) de pessoas, lugares, objetos e fatos. A memória procedural ou implícita, que se relaciona aos hábitos e ao aprendizado mecânico (ou condicionado) está relacionada com os circuitos subcorticais ou cerebelares. A memória do hipocampo é a memória de trabalho e de aprendizado e a evocação das memórias de curta e longa duração. O TEPT é marcado por sintomas envolvendo a construção e a evocação de memórias.
\end{abstract}

Esse laço entre a emoção/memória tem início no momento no qual a memória se forma, quando a atenção e a concepção vão determinar se esta experiência vivida será a posteriori lembrada ou não. No TEPT, há uma relação do evento estressor com a memória, a qual leva a uma recordação, cujos estímulos - diferentes do evento, mas relacionados a ele - podem servir como gatilho para lembranças, desencadeando reações (FREITAS, 2013). Portanto, pode-se dizer que artigos com teor emocional atraem a atenção do indivíduo automaticamente, fixando-se melhor na memória. 
Segundo Pregnolato (2018), qualquer pessoa é suscetível a desenvolver TEPT em qualquer idade se exposta a uma situação de alto impacto, cujas lembranças e despertar de sensações/emoções são desencadeados das maneiras mais diversas. O autor também enfatiza que, apesar da maior prevalência do TEPT ocorrer em locais ou com pessoas naturalmente mais propensas ou diretamente ligadas a um desastre, há estudos recentes que relacionam o TEPT a hábitos comuns do cotidiano, levantando a suspeita de que o transtorno pode surgir mesmo se este impacto tiver sido por meio de conteúdo veiculado em mídias, transformando emocionalmente quem o assiste.

Em virtude dos estudos da psiquiatria mencionados, é possível analisar a estreita relação entre o indivíduo com um determinado objeto quando este, de alguma maneira, remete às emoções causadas por um evento traumático. Para este artigo, alçou-se essa ligação entre a camisa da Chapecoense edição especial e a tragédia ocorrida em Medellín, cujas emoções remetidas por intermédio do objeto podem despertar as mais diversas reações em um indivíduo, reações objetivas e individuais, logo, o usuário não precisa estar necessariamente ligado de forma direta ao ocorrido para obter alguma emoção concreta para com o objeto. Desta forma, foi realizado um questionário digital distribuído virtualmente de forma aleatória aos respondentes. Não foi utilizado nenhum critério como faixa etária, sexo, familiares ou pessoas vinculadas ao time para responder o questionário, visto que a abrangência do acidente tomou proporções a nível mundial e qualquer pessoa pode ter sido impactada por seus efeitos. Neste estudo foram coletadas respostas de 134 voluntários respondentes ao questionário, as quais foram analisadas com base nos parâmetros do Design Emocional, seguindo a proposta de 14 emoções sugerida por Desmet (2002), com o intuito de compreender e ilustrar como um artefato impregnado de simbolismo pode afetar positiva ou negativamente o público pesquisado.

\subsection{Camisa Chapecoense II 2018 s/no La Pasion}

Como objeto de análise emocional para o presente artigo, os autores optaram pela Camisa Chapecoense II 2018 s/no La Pasion, por a considerarem um artefato rico de significações para o parâmetro de análise. A camisa refere-se ao time Associação Chapecoense de Futebol, fundado em 10 de maio de 1973 na cidade de Chapecó, Estado de Santa Catarina, o qual possui seis títulos no Campeonato Catarinense de Futebol. A trajetória de ascensão do clube teve início com o acesso à 
série D do Campeonato Brasileiro de Futebol e posteriormente à série C, ambos no ano de 2009. Em 2012, conquistou o acesso à série B, fato inédito em sua história, e em 2013, o clube atingiu a série A, surpreendendo por seu bom desempenho. Em agosto de 2016, iniciou sua trajetória na participação da Copa Sul-Americana pela segunda vez (a primeira ocorrida no ano anterior). Com jogo marcante na semifinal, o clube garantiu sua vaga na grande final do campeonato contra o Atlético Nacional de Medellín, na Colômbia, causando grande expectativa entre os torcedores e a cidade de Chapecó. Neste momento, o time passou a representar o Brasil na Copa Sul-Americana, ganhando simpatizantes e torcedores por todo o país.

Em 29 de novembro de 2016, o avião que transportava o time - juntamente com comissão técnica, dirigentes, jornalistas e convidados - para a cidade de Medellín (Colômbia) para o primeiro jogo da final, chocou-se contra um monte, vitimando 71 dos 77 passageiros, causando comoção nacional e internacional. O impacto do acidente foi imensurável, e homenagens em diversos formatos foram e seguem sendo realizadas aos chamados "guerreiros", vítimas do acidente aéreo (CHAPECOENSE, 2018).

Figura 1 - Camisa Chapecoense II 2018 s/no La Pasion.

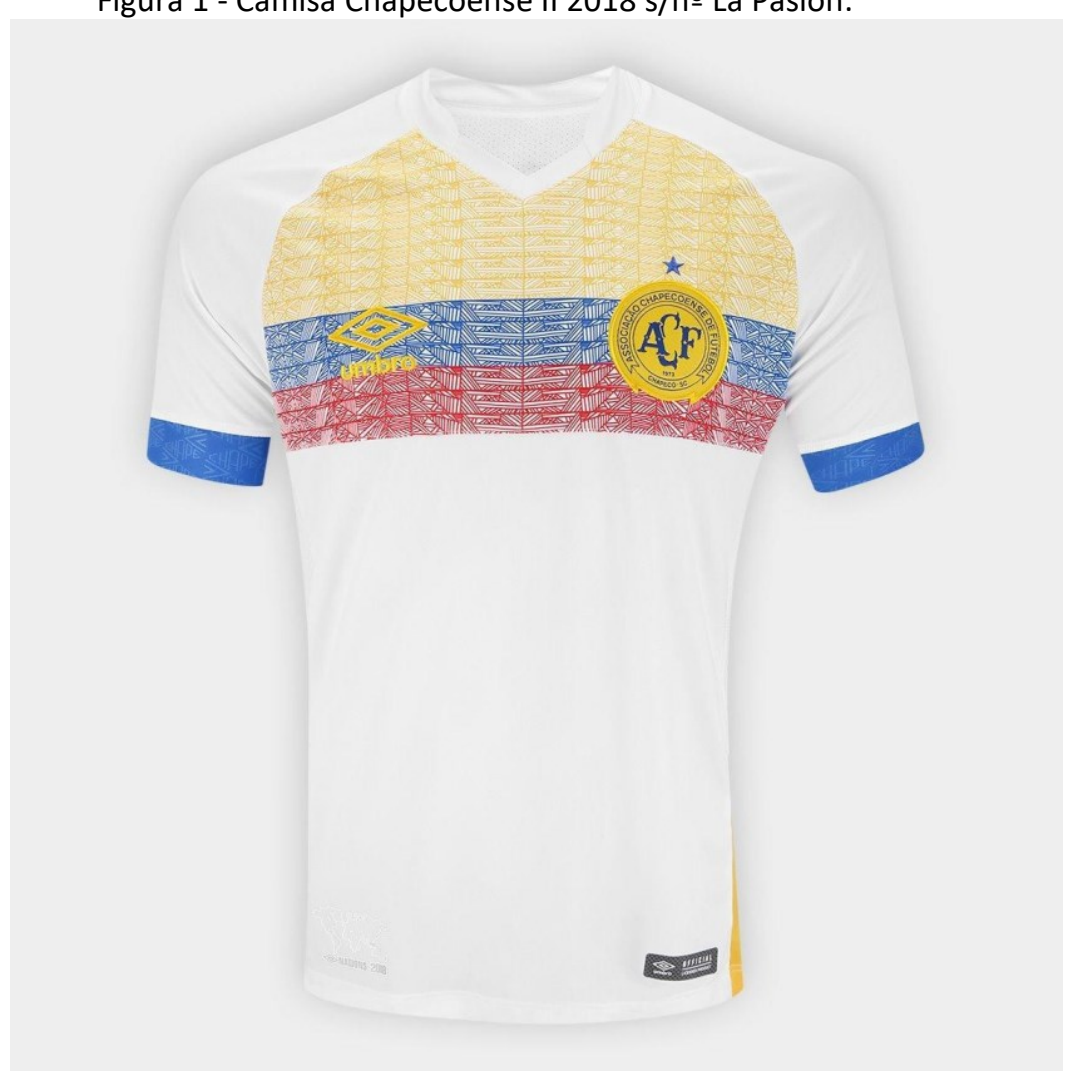

Fonte: Loja da Chape (2018). 
Para a Camisa Chapecoense 2018, a Umbro - marca de roupa esportiva fortemente presente no futebol - optou por homenagear a Colômbia, cujo povo não mediu esforços para apoiar o clube após a tragédia. Simbolizando a união entre as duas torcidas (dos times de Medellín e Chapecó, respectivamente), representa a irmandade e conexão que sobrepõem a disputa do futebol (LOJA DA CHAPE, 2018). Logo, é possível apontar que tal estratégia emocional utilizada pela Umbro pode trazer como consequência uma identificação por parte dos usuários com a mesma, assim como o benefício de fidelização da marca, atestando a reflexão de Damásio (2012) sobre o quanto a ideia das emoções influenciam as escolhas e decisões, ou seja, este posicionamento da Umbro pode levar ao aumento do consumo de seus artigos por parte do consumidor já existente da marca e também de novos torcedores, em razão da iniciativa de desenvolver um produto com ênfase simbólica.

Em virtude do acontecimento, parte-se da premissa de que sentimentos relacionados a produtos são recursos valiosos a serem utilizados por designers. Há a intenção de trazer estímulos, seja ele percebido e sentido pelos usuários de maneira consciente ou não, criando vínculos afetivos e fidelização, como um compromisso entre as partes. Desmet (2002) e Norman (2008) mostram, portanto, que as emoções não são manipuláveis, mas ao compreender o que provoca o processo emocional do usuário, pode-se projetar para a emoção. Logo, as emoções despertadas no objeto de estudo se tornaram um dos interesses para esta pesquisa, a fim de elucidar quais emoções podem, neste caso, ser causadas por um determinado produto, embora este esteja relacionado a uma situação negativa como a tragédia.

\section{RESULTADOS E DISCUSSÕES}

O questionário elaborado para análise da camisa foi respondido por 134 pessoas, dentre o número total de respondentes, 82,1\% (110 pessoas) consideram-se torcedores do time. O público foi segmentado em 73 pessoas do sexo feminino (54,5\%) e 61 pessoas do sexo masculino (45,5\%). A faixa etária mais presente foi de 18 a 25 anos, sendo estes 65 dos entrevistados (48,5\%), seguida por 22 pessoas de 26 a 35 anos (16,4\%), 17 pessoas de 46 a 55 anos (12,7\%), 15 pessoas de 36 a 45 anos (11,2\%), nove pessoas abaixo de 18 anos $(6,7 \%)$ e seis pessoas acima de 56 anos (4,5\%). Foram selecionadas 14 emoções propostas por Desmet classificadas em quatro níveis: não sinto, sinto um pouco, sinto e sinto intensamente. As emoções consideradas negativas quase não foram sentidas, 
Letícia Casagrande Dal Bello, Luana Ferreira Graziano, Célio Teodorico dos Santos, Fabiana Rodrigues da Silva, Ricardo de Moura Mendonça, Fabíola Barbosa Beltrão

enquanto as consideradas positivas foram sentidas em diversos níveis, conforme mostra o Quadro 1.

Quadro 1 - Resultado do questionário aplicado.

\begin{tabular}{|c|c|c|c|c|c|}
\hline Emoção & Não Sinto & Sinto um pouco & Sinto & $\begin{array}{c}\text { Sinto } \\
\text { intensamente }\end{array}$ & Total \\
\hline Orgulho & 13 & 26 & 70 & 25 & 134 \\
\hline Desejo & 36 & 45 & 46 & 7 & 134 \\
\hline Esperança & 23 & 35 & 52 & 24 & 134 \\
\hline Alegria & 24 & 38 & 57 & 15 & 134 \\
\hline Interesse & 34 & 35 & 51 & 14 & 134 \\
\hline Encantamento & 29 & 41 & 51 & 13 & 134 \\
\hline Diversão & 36 & 49 & 39 & 10 & 134 \\
\hline Satisfação & 28 & 38 & 56 & 12 & 134 \\
\hline Tédio & 119 & 10 & 5 & 0 & 134 \\
\hline Medo & 101 & 25 & 5 & 3 & 134 \\
\hline Indiferença & 109 & 19 & 6 & 0 & 134 \\
\hline Aversão & 121 & 10 & 3 & 0 & 134 \\
\hline Desprezo & 127 & 6 & 1 & 0 & 134 \\
\hline Tristeza & 60 & 43 & 25 & 6 & 134 \\
\hline TOTAL & $\mathbf{8 6 0}$ & $\mathbf{4 2 0}$ & $\mathbf{4 6 7}$ & $\mathbf{1 2 9}$ & $\mathbf{1 8 7 6}$ \\
\hline
\end{tabular}

Fonte: Elaborado pelos autores (2018).

Considerando as 14 emoções classificadas por 134 pessoas, obteve-se um total de 1.876 respostas. Destas, 860 (45,84\%) foram categorizadas como 'não sinto', enquanto as outras 1.016 $(54,16 \%)$ refletem que o indivíduo sente algum nível de emoção com a peça, reafirmando sua dimensão simbólica.

A emoção mais sentida, considerando todos os níveis, foi 'Orgulho' (90,3\%), seguida por 'Esperança' (82,83\%) e 'Alegria' (82,1\%). As emoções mais intensamente sentidas foram 'Orgulho' e 'Esperança', com 18,66\% e 17,9\% das respostas neste nível, respectivamente. De acordo com Desmet e Hekkert (2001, p. 4), "as respostas emocionais em relação a um produto são determinadas pela forma como o avaliamos para corresponder ao nosso conjunto de metas, padrões e atitudes". Neste caso, o orgulho se mistura a um prazer psíquico, social e ideológico apontado por Jordan (2001), e com efeito sinestésico carregado de sensações simultâneas provocadas e motivadas pelo fenômeno em si, representado aqui pela camisa, onde os voluntários pesquisados demonstraram orgulho em fazer parte deste grupo. As emoções de esperança e alegria também mais evidenciadas nesta pesquisa como uma preocupação emocional positiva 
remetem ao nível reflexivo de Norman (2008), provocado por estímulos afetivos, lembranças e crenças, que pode ser vista como uma dimensão simbólica cultural e de pertencimento.

Padrões dos fenômenos sociais são referências úteis para auxiliar na avaliação do comportamento humano, e neste estudo, os estímulos emocionais positivos ou negativos, ou seja, aqueles considerados bons e os considerados ruins. Os estímulos ruins provocam aversão e afastamento; a tristeza apresentou um índice elevado, tendo em vista as circunstâncias experienciadas pelo grupo pesquisado. As emoções menos sentidas foram 'Desprezo' (94,77\%), 'Aversão' (90,3\%) e 'Tédio' (88,81\%). Inclusive, emoções como 'Indiferença', 'Aversão' e 'Tédio' não obtiveram nenhuma resposta no nível mais intenso (0\%). Das emoções negativas, há destaque para a 'Tristeza', na qual 55,22\% das respostas relatam algum nível de sentimento, pode ser relacionado à tragédia com a qual a camisa está relacionada e o clube enquanto agremiação.

Nem todas as emoções são estimuladas na mesma intensidade e variam de um indivíduo ao outro, mesmo assim, é possível relacionar e obter alguns padrões de comportamento para validar estudos em design e emoção. Questionados se haviam sentido alguma outra emoção, 11 pessoas relataram sentir 'Saudade', a qual uma delas citou "sentir saudade de um amigo que perdeu no acidente”. Quatro pessoas citaram 'Gratidão', e outras quatro citaram 'Lembrança'. Uma pessoa citou 'Nojo'. Acredita-se que todas essas falas tenham relação com o acidente, sendo 'Gratidão' ao povo colombiano e/ou ao time, 'Lembrança' relacionado às vítimas, e 'Nojo' supõe-se corresponder aos erros cometidos que levaram ao acidente aéreo - suposições especulativas feitas aqui pelos autores deste estudo.

Ao abrir espaço para acrescentar falas, quatro pessoas citaram sentir falta da cor Verde, característica do time Chapecoense. Uma pessoa citou a responsabilidade pelo acidente, dizendo que "normas de segurança coletiva jamais devem ser negligenciadas", sendo reforçado por outro que disse sentir-se indignado com a irresponsabilidade do ocorrido. Outra pessoa não compreendeu o uso das cores, possivelmente não associando o amarelo, azul e vermelho com a bandeira da Colômbia.

Fica evidente, portanto, que independentemente da qualidade de emoção sentida pelo indivíduo, o objeto relacionado a um evento de grandes proporções (como no caso, a uma tragédia), remete a sentimentos individuais por parte dos usuários. Grande parte dos sentimentos 
trazidos pela camisa da Chapecoense, são positivos, o que aponta uma empatia pelos envolvidos na tragédia e tornando, portanto, válida a atitude da marca em confeccionar tal produto.

Logo, observa-se que o design emocional aplicado a uma peça de vestuário é significativo, resultando na possibilidade de criar vínculos afetivos entre os usuários, marca e clube. Neste caso, a partir dos estímulos provocados no contexto aqui discutido, foi possível perceber que consumidores e torcedores entenderam se tratar de uma homenagem, no entanto, para os envolvidos direta e indiretamente no ocorrido, esta iniciativa contribuiu para preservação da memória como um marco emocional e histórico. Quanto a alterações e melhorias no produto, possivelmente o acréscimo da cor verde (característica do time) apontada pelos respondentes fortaleceria o vínculo com o usuário.

Para Desmet e Hekkert (2001), a pesquisa pode fornecer insights ao design, para investigar um usuário específico considerando-os como sujeito do processo e não somente como meros sujeitos da pesquisa, ou seja, trazer esses valores emocionais para dentro do processo de design, para um melhor entendimento das preocupações emocionais e das interações dessas pessoas com produtos.

\section{CONSIDERAÇÕES FINAIS}

Partindo do estudo e compreensão do Design Emocional e dos resultados do questionário aplicado, pode-se afirmar que o artefato selecionado como objeto de análise possui forte carga emocional devido ao simbolismo que carrega.

Ao longo do artigo, foram abordados conceitos sobre design emocional sob as colocações de autores como Norman (2008), que apresenta os três níveis do design emocional (visceral, comportamental e reflexivo), e Desmet (2002), que classifica em 14 as emoções que um dado objeto pode causar, apresentando conceituações e métodos pertinentes a posterior análise. Optouse por pautar a análise dentro das colocações de Desmet por melhor atenderem aos requisitos necessários à compreensão do objeto de estudo, a camisa de edição especial da Chapecoense, escolhida pelos fatores altamente simbólicos que apresenta, tornando-se um objeto adequado para a abordagem proposta por centrar-se no nível reflexivo. Observou-se com a aplicação do questionário, que a camisa despertou diferentes emoções tanto em torcedores quanto em não 
torcedores, em sua maioria emoções positivas, com algumas colocações pontuais em relação à tragédia a qual a peça remete.

Na visão psiquiátrica do TEPT, observou-se que os usuários recebem estímulos visuais, e tais estímulos são levados a uma parte do cérebro humano responsável pelo reconhecimento e evocação da memória afetiva, e por consequência, não só atraem a atenção do usuário como também criam empatia com o objeto devido ao simbolismo ali contido. No objeto estudado, é perceptível a relação entre o simbólico representado e a receptividade do produto pelo público, despertando lembranças e emoções. Estímulos emocionais relacionados aos níveis social, psíquico e ideológico foram evidenciados pelo grupo pesquisado.

Os resultados obtidos, com a abrangência de 134 pessoas respondentes, mais da metade (cerca de 54,16\%) dos entrevistados expressaram algum tipo de sentimento perante a camisa, mesmo os não torcedores do time. Independentemente de sentimentos negativos ou positivos, tal resultado demonstra que os estímulos emocionais representados pela camisa que envolveu uma tragédia de grandes proporções, causou afinidade, empatia e comoção por parte dos indivíduos, resultando, portanto, em satisfação e reconhecimento pela homenagem através do objeto pela preservação e memória aos envolvidos.

Assim, foi possível perceber que o design emocional tem a intenção de inserir no mercado produtos e serviços com o propósito de despertar emoções e sentimentos nos usuários, sendo capaz de influenciar a escolha de um determinado artefato em detrimento de outro. Conclui-se que a camisa escolhida como objeto de análise deste estudo opera no nível reflexivo, de acordo com as classificações de Norman (2008), visto tratar-se de um objeto provido de elementos ou atributos numa perspectiva das emoções, uma vez suportado por uma história trágica e seu significado carregado de valores simbólicos e de emoções expressadas em diferentes níveis. Quanto à proposta de Desmet (2002), foi possível averiguar as emoções mais frequentemente despertadas pelo objeto de estudo, proporcionando uma melhor compreensão de como as emoções afetam a percepção do usuário na interação com produtos.

Apesar dos estudos em Design e Emoção serem recentes, as publicações e autores referência na área comprovam a importância para o campo do design para avaliar as preocupações emocionais das pessoas em relação aos seus objetivos e atitudes, investigando os estímulos quando das interações com produtos ou serviços. 


\section{REFERÊNCIAS}

APA. Manual diagnóstico e estatístico de transtornos mentais: DSM-V. 5. ed. Porto Alegre: Artmed, 2014.

BISSON, I. Jonathan; COSGROVE, Sarah; LEWIS, Catrin; ROBERTS, Neil P.. Post-traumatic stress disorder. BMJ: Clinical Research, [s.I.], n. 351, h6161, nov. 2015. Disponível em:

https://doi.org/10.1136/bmj.h6161. Acesso em: 30 out. 2019.

CHAPECOENSE. Nossa história. 2018. Disponível em: https://chapecoense.com/pt/nossa-historia. Acesso em: 30 out. 2019.

CIETTA, Enrico. A economia da moda. 1. ed. São Paulo: Estação das Letras e Cores, 2017.

CRANE, Diana. A moda e seu papel social: classe, gênero e identidade das roupas. São Paulo: Editora Senac São Paulo, 2006.

DAMÁSIO, Antonio R. Em busca de Espinosa: prazer e dor na ciência dos sentimentos. São Paulo: Companhia das Letras, 2004.

DAMÁSIO, Antonio R. O erro de Descartes: emoção, razão e o cérebro humano. 3. ed. São Paulo: Companhia das Letras, 2012.

DESMET, Pieter. Designing Emotional. 2002. Tese (Doutorado em Tecnologia) - Technische Universiteit Delft, Izegem, 2002.

DESMET, Pieter; OVERBEEKE, Kees; TAX, Stefan. Design products with added emotional value: development and application of an approach for research for research through design. The Design Journal, [s.l.], v. 4, n. 1, p. 32-47, 2001.

FONSECA, João José Saraiva da. Metodologia da pesquisa científica. Apostila do Curso de Especialização em Comunidades Virtuais de Aprendizagem. Fortaleza: UECE, 2002. Apostila.

FREITAS, Ana Clelia de Freitas. Transtorno de estresse pós-traumático. [S.I.], 26 abr.2013. Disponível em: http://conteudojuridico.com.br/artigo,transtorno-de-estresse-postraumatico,43166.html. Acesso em: 30 out. 2019.

GARCIA, Carol; MIRANDA, Ana Paula de. Moda é comunicação: experiências, memórias, vínculos. São Paulo: Editora Anhembi Morumbi, 2005.

GIL, Antonio Carlos. Métodos e técnicas de pesquisa social. 5. ed. São Paulo: Atlas, 2008.

LOJA DA CHAPE. Camisa Chapecoense II 2018 S/N La Pasion Torcedor Umbro Masculina. [S.I.], 2018. Disponível em: https://www.lojadachape.com.br/camisa-chapecoense-ii-2018-sn-la-pasiontorcedor-umbro-masculina-branco+azul-D21-2179-044\#features. Acesso em: 30 out. 2019. 
MARCONI, Mariana de Andrade; LAKATOS, Eva Maria. Fundamentos de Metodologia Científica. 8. ed. São Paulo: Atlas, 2017.

MIRANDA, Ana Paula de. Consumo de moda: a relação pessoa-objeto. São Paulo: Estação das Letras e Cores, 2008.

NORMAN, Donald A. Design Emocional: por que adoramos (ou detestamos) os objetos do dia a dia. Rio de Janeiro: Rocco, 2008.

PIFFERO, Victoria de Menezes; PIZZATO, Gabriela Zubaran de Azevedo. Uma contribuição do Design Emocional para o Design de Superfície: um estudo de caso da ciclovia Van Gogh-Roosegaarde. ModaPalavra e-periódico, Florianópolis, v. 11, n. 21, p. 56-78, jan./jun. 2018. Disponível em: http://www.revistas.udesc.br/index.php/modapalavra/article/view/10376. Acesso em: 30 out. 2019.

PREGNOLATO, Mariuza. Transtorno de estresse pós-traumático versus novos hábitos: o TEPT - o transtorno de estresse pós-traumático requer mesmo que tenha havido um trauma?. [S.I.], [201-]. Disponível em: http://mariuzapregnolato.com.br/transtorno-de-estresse-pos-traumatico-versusnovos-habitosterapia-comportamental-cognitivaterapia-de-traumaterapeuta-em-sao-paulo/. Acesso em: 30 out. 2019.

PRONI, Giampaolo. A semiótica e a moda. In: SORCINELLI, Paolo (org.). Estudar a Moda: corpos, vestuários, estratégias. São Paulo: Editora Senac São Paulo, 2008. 